\title{
Study Subject Payment Method Code
}

National Cancer Institute

\section{Source}

National Cancer Institute. Study Subject Payment Method Code. NCI Thesaurus. Code C94155.

A coded value specifying the primary payer/insurance carrier information at the time of treatment on a study. 